\title{
Forecasting Future Trends in Obesity across Europe: The Value of Improving Surveillance
}

\author{
Elisa Pineda ${ }^{a} \quad$ Luz Maria Sanchez-Romero $^{a} \quad$ Martin Brown $^{b}$ \\ Abbygail Jaccard $^{\mathrm{b}}$ Jo Jewell ${ }^{\mathrm{c}}$ Gauden Galea ${ }^{\mathrm{c}}$ Laura Webber ${ }^{\mathrm{b}}$ \\ João Bredac

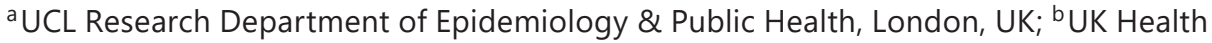 \\ Forum, London, UK; ' ${ }^{\mathrm{N}}$ Nutrition, Division of Non-Communicable Diseases and Health \\ Promotion through the Life-Course, WHO Regional Office for Europe, Copenhagen, \\ Denmark
}

\section{Keywords}

BMI · Obesity · Epidemiology · Modelling · Policy

\begin{abstract}
Objective: To project the prevalence of obesity across the WHO European region and examine whether the WHO target of halting obesity at 2010 levels by 2025 is achievable. Methods: $\mathrm{BMI}$ data were collected from online databases and the literature. Past and present BMI trends were extrapolated to 2025 using a non-linear categorical regression model fitted to nationally representative survey data. Where only 1 year of data was available, a flat trend was assumed. Where no data were available, proxy country data was used adjusted for demographics. Results: By 2025, obesity is projected to increase in 44 countries. If present trends continue, 33 of the 53 countries are projected to have an obesity prevalence of $20 \%$ or more. The highest prevalence is projected for Ireland (43\%, 95\% confidence interval (CI): $28-58 \%$ ). Lithuania, Finland, and the Netherlands were each estimated to have an absolute increase of 2 percentage points in the prevalence of obesity between 2015 and 2025. Discussion: The quality of BMI data across Europe is highly variable, with fewer than $50 \%$ of the 53 countries having measured nationally representative data and often not enough data to interpret projections meaningfully. Nevertheless, the prevalence of obesity in the European Region appears to be increasing in most countries and, with it, the health and economic burden of its
\end{abstract}

Elisa Pineda and Luz Maria Sanchez-Romero are joint first authors, and Gauden Galea and João Breda are joint last authors. 
Pineda et al.: Forecasting Future Trends in Obesity across Europe: The Value of Improving Surveillance

associated diseases. This paints a concerning picture of the future burden of obesity-related noncommunicable diseases across the region. Greater and continued effort for the implementation of effective preventive policies and interventions is required from governments.

(C) 2018 The Author(s)

Published by S. Karger GmbH, Freiburg

\section{Introduction}

The prevalence of obesity has increased substantially over the past three decades [1]. Worldwide in 2014, over 600 million adults (13\% of the total adult population) are classified as obese [2], comprising $11 \%$ of all men and $15 \%$ of all women [1]. In the European Region, the prevalence of obesity is estimated to be $23 \%$ [1]. The prevalence of obesity has increased between 2010 and 2014, and has tripled since 1980 [3, 4].

Obesity is a chronic disease and an important risk factor for many other diseases, placing substantial pressure on individuals and health systems globally. In the most recent Global Burden of Disease Study [4], a high BMI was the leading risk factor, accounting for 4.4 million deaths and 134.0 million disability-adjusted life-years (DALYs). Pre-obesity and obesity are responsible for approximately 35\% of all cases of ischemic heart disease, 55\% of hypertension, and around $80 \%$ of type 2 diabetes. High BMI also contributes to mortality from all causes in Europe [5, 6].

On average, European Union countries spend approximately $7 \%$ of their health care budgets on obesity-related diseases [7-9]. If obesity rates continue to rise in line with current trends, the burden of these diseases and the associated health care costs will be substantial.

Estimates of future obesity trends will inform researchers, policy-makers and public health practitioners about the evolution of the prevalence. Future trends in obesity could also be used as benchmarks to set goals for reducing obesity, to guide policy and interventions to slow the epidemic, to assess the effectiveness of interventions that have already been implemented, and to plan priorities for health care resource allocation [10]. Obesity trends may also be used to urge governments to implement preventive approaches to reducing obesity, given the related health and economic implications of not doing so.

WHO, Member States in the European Region, and the European Commission have taken steps to address the obesity epidemic through several programs, policies, strategies, and initiatives over the past 10 years [7,11-14]. The WHO has also set up several surveillance systems to monitor progress in reducing obesity and its risk factors, such as the European Database on Nutrition, Obesity and Physical Activity (NOPA) [15] and the European Childhood Obesity Surveillance Initiative (COSI) [16].

In the present study, we projected trends in obesity (BMI $\geq 30 \mathrm{~kg} / \mathrm{m}^{2}$ ) forwards to 2025 for each of the 53 WHO Member States in the European Region as well as each for of the countries in the UK (England, Northern Ireland, Scotland, and Wales). The study also indicates how much work remains to be done in order to achieve the voluntary health target of halting the rise in obesity and effectively reducing the health and socioeconomic consequences [17].

The specific objectives were to assess the quality and accessibility of the data available in the 53 countries in the WHO European Region for measuring the prevalence of obesity, and to project trends in obesity from 2015 to 2025 on the basis of past and current values for BMI. 
Pineda et al.: Forecasting Future Trends in Obesity across Europe: The Value of Improving Surveillance

\section{Material and Methods}

\section{BMI Data Extraction}

Data on BMI were collected for each of the 53 WHO Member States in the European Region and each of the countries in the UK between 1990 and August 2015, from the WHO BMI database [18], national statistical databases, public health institutions and health surveillance reports, and the PubMed and Science Direct databases. Data were also collected by personal communication with researchers and public health officers. Both measured and self-reported data were included in the analyses. Data collected before 2000 were later dropped from the analysis as they were deemed too old to make meaningful inferences of future trends. These data were: Andorra 1997; Austria 1999; Belgium 1997; Croatia 1997-1999; Czech Republic 1993, 1996, 1999; France 1997; Germany 1999; Greece 1999; Iceland 1990; Kazakhstan 1999; Kyrgyzstan 1993, 1997; and England before 2000 (given the large amount of data available). Annex 1 presents the lists of references used for our analyses (available at http://content.karger.com/ProdukteDB/produkte.asp?doi=492115).

Data sources were included if they satisfied both of the following criteria: BMI was categorized according to WHO definitions [19], and data were presented stratified by age group and sex. When data were reported by sex or age alone, the authors were contacted for more details.

BMI data for adult populations ( $\geq 20$ years) were compiled into country-specific standardized files. For each country and each year of data obtained, the files included: information on the percentage prevalence in a given year of normal weight $\left(\leq 25 \mathrm{~kg} / \mathrm{m}^{2}\right)$, pre-obesity $\left(25-29.9 \mathrm{~kg} / \mathrm{m}^{2}\right)$ and obesity $\left(\geq 30 \mathrm{~kg} / \mathrm{m}^{2}\right)$ according to the WHO classification of BMI [20] stratified by sex in 5-year age groups and the sample sizes for each age group. When only total population sample sizes were reported, the specific sample sizes of each age group were calculated using age-sex distributions for that country from United Nations population statistics [21].

Assessment of Data Quality and Accessibility

To assess the quality and accessibility of BMI surveillance data across Europe, we developed a scoring system with five parameters: data points, measured, national, sample size, and freely available. These scores were used to help interpret the accuracy of the projections.

i) Data points indicate the number of years of data for each country used to estimate obesity projections. ii) Measured indicates whether the anthropometric data used to estimate BMI were measured directly or self-reported. iii) National refers to data that were nationally representative of a country. iv) Sample size indicates whether the total analytical sample size was reported and whether it was stratified by age group and/or sex. (v) Freely available indicates whether the data were obtained from publicly available sources or by personal contact (i.e. with researchers, ministry of health personnel or other institutions).

Each country's data were assessed for the five components. We gave a score of 0 or 1 for four of the five components, with the exception of sample size, which was given one point if the sample sizes were stratified by age group and sex, 0.5 points if only the total sample size was reported, and 0 points if no sample size was presented. Each data point could have a maximum score of 5. To estimate the total data score for each country, we summed the scores obtained for each data point for each country. More details on how the scores were given for each parameter is provided in table 1.

Categorization and Processing of BMI Data

Detailed statistical analysis is presented in Annex 2 (available at http://content.karger.com/ProdukteDB/ produkte.asp?doi=492115), in brief:

The source data were sorted into three mutually exclusive BMI categories: normal weight $\left(\leq 25 \mathrm{~kg} / \mathrm{m}^{2}\right)$, pre-obese $\left(25-29.9 \mathrm{~kg} / \mathrm{m}^{2}\right)$, and obese $\left(\geq 30 \mathrm{~kg} / \mathrm{m}^{2}\right)[18]$.

BMI data for wide age groups (e.g. 15-year age groups) were evenly divided into five-year groups, dividing the sample size by 3 and tripling the BMI variance of the estimates, in order to take account of the increased variance around the prevalence figures for each age group. The BMI variance was calculated from the equation

Variance $=p(1-p) / n$

where $\mathrm{p}$ is the prevalence of obesity and $\mathrm{n}$ the sample size of the total population.

When data on BMI prevalence were available for only two categories, the remaining category was inferred by subtracting the sum of the two categories from 100. For example, if data only on pre-obesity and 
Pineda et al.: Forecasting Future Trends in Obesity across Europe: The Value of Improving Surveillance

Table 1. Scoring parameters

\begin{tabular}{llll}
\hline Component & 1 point & 0.5 points & 0 points \\
\hline Data points & $\begin{array}{l}\text { For each data point used for } \\
\text { the projections }\end{array}$ & \\
\hline Measured & $\begin{array}{l}\text { Measured anthropometric } \\
\text { data }\end{array}$ & $\begin{array}{l}\text { Self-reported } \\
\text { anthropometrics }\end{array}$ \\
\hline National & Nationally representative & Regional survey \\
\hline Sumple size & $\begin{array}{l}\text { Available and stratified by } \\
\text { age group and sex }\end{array}$ & $\begin{array}{l}\text { Reported only total } \\
\text { population or total sample } \\
\text { of males and females }\end{array}$ & No population size reported \\
\hline $\begin{array}{l}\text { Freely available } \\
\text { Information obtained from a } \\
\text { report, article or webpage }\end{array}$ & $\begin{array}{l}\text { Information obtained by } \\
\text { personal contact }\end{array}$ \\
\hline
\end{tabular}

obesity were available, the percentage of individuals of normal weight was 100 - (pre-obese + obese). When only one category of BMI data was available (pre-obese or obese), the data source was not used since we were unable to calculate the missing data.

\section{Projection Statistical Analysis}

BMI trends were estimated to 2025 adjusted for age and sex population distributions for all countries separately in a non-linear, multivariate, categorical regression model fitted to cross-sectional BMI data from each country; outliers falling outside the $95 \%$ confidence interval (CI) were removed. These were generally in the older age groups where sample sizes were small: Denmark 75+ male, 70-74 male 2006; Estonia 60-64 male, 65-69 male, 70-74 male, 75+ male 2000, 2002, 2004, 2006, 2010 and 2014; Finland 65-69 male, 70-74 male, 70-74 female, 75+ female, 75+ male 1998, 1999, 2001, 2002, 2003, 2004, 2005, 2006, 2007, 2009-2014, Latvia 65-69 female, 65-69 male, 70-74 female and male, 75+ female and male all but 2008; Bulgaria 55-59 male 2004; and Slovenia 75+ female. The method is described in detail previously by Wang and colleagues [9] and McPherson et al [24]. To estimate the future trends, it was necessary to use different methods for BMI data categorization and processing obesity due to the heterogeneity of the data found to feed the model. For example, for Monaco and San Marino BMI data were not available so 'proxy' country data were used (using the BMI data of France and Italy for each country respectively) adjusted for country demographics. Where only mean data were available, a distribution was constructed mathematically and a static (flat) trend was extrapolated forward. Further details of these methods are described in Annex 2 (available at http://content.karger.com/ProdukteDB/produkte.asp?doi=492115). The software used for this program was written in $\mathrm{C}++$.

\section{Results}

\section{Data Quality and Accessibility Assessment}

The evaluation of data quality and accessibility for each of the 53 countries is presented in table 2. The total score given for each country was provided. Those countries with measured data are highlighted in bold to illustrate the few countries with measured data.

Most of the Member States assessed provided at least two data points that were appropriate for the projections. England, the Russian Federation, and Finland obtained the highest scores in terms of data quality and accessibility, with total scores of 70, 68 and 64 respectively. For Monaco and San Marino, no data were found. We used France and Italy as proxy 
Pineda et al.: Forecasting Future Trends in Obesity across Europe: The Value of Improving Surveillance

Table 2. Total data score per country

\begin{tabular}{|c|c|c|c|c|c|c|}
\hline Country & $\begin{array}{l}\text { No. of data } \\
\text { points }\end{array}$ & Measured & National & $\begin{array}{l}\text { Sample } \\
\text { size }\end{array}$ & $\begin{array}{l}\text { Freely available/ } \\
\text { accessible }\end{array}$ & Total \\
\hline England & 14 & 14 & 14 & 14 & 14 & 70 \\
\hline Russian Federation* & 17 & 0 & 17 & 17 & 17 & 68 \\
\hline Finland & 16 & 0 & 16 & 16 & 16 & 64 \\
\hline Netherlands & 15 & 0 & 15 & 0 & 15 & 45 \\
\hline Scotland & 9 & 9 & 9 & 9 & 9 & 45 \\
\hline Lithuania & 9 & 0 & 9 & 9 & 9 & 36 \\
\hline Estonia & 9 & 0 & 9 & 9 & 8 & 35 \\
\hline Italy & 10 & 0 & 10 & 9 & 5 & 34 \\
\hline Ireland & 7 & 5 & 7 & 7 & 7 & 33 \\
\hline Wales & 8 & 0 & 8 & 8 & 8 & 32 \\
\hline Greece & 9 & 0 & 9 & 9 & 1 & 28 \\
\hline France & 8 & 0 & 8 & 3.5 & 8 & 27.5 \\
\hline Germany & 8 & 1 & 8 & 7.5 & 3 & 27.5 \\
\hline Sweden & 7 & 0 & 7 & 5.5 & 7 & 26.5 \\
\hline Turkey & 6 & 6 & 2 & 6 & 6 & 26 \\
\hline Latvia & 6 & 0 & 6 & 6 & 6 & 24 \\
\hline Norway & 6 & 0 & 6 & 6 & 6 & 24 \\
\hline Kyrgyzstan & 5 & 3 & 5 & 4.5 & 3 & 20.5 \\
\hline Belgium & 5 & 0 & 5 & 5 & 5 & 20 \\
\hline Czech Republic & 5 & 0 & 5 & 5 & 5 & 20 \\
\hline Switzerland & 5 & 0 & 5 & 5 & 5 & 20 \\
\hline Azerbaijan & 5 & 0 & 5 & 5 & 4 & 19 \\
\hline Israel & 6 & 0 & 6 & 6 & 1 & 19 \\
\hline Poland & 5 & 0 & 4 & 4.5 & 5 & 18.5 \\
\hline Malta & 5 & 0 & 5 & 3 & 5 & 18 \\
\hline Portugal & 5 & 0 & 5 & 3 & 5 & 18 \\
\hline Austria & 4 & 1 & 4 & 4 & 4 & 17 \\
\hline Ukraine & 4 & 2 & 3 & 3.5 & 4 & 16.5 \\
\hline Iceland & 5 & 0 & 5 & 5 & 1 & 16 \\
\hline Spain & 4 & 0 & 4 & 4 & 4 & 16 \\
\hline Northern Ireland & 4 & 4 & 4 & 4 & 4 & 16 \\
\hline Armenia & 4 & 2 & 3 & 3.5 & 3 & 15.5 \\
\hline Slovakia & 4 & 0 & 4 & 3.5 & 4 & 15.5 \\
\hline Croatia & 3 & 3 & 3 & 3 & 3 & 15 \\
\hline Kazakhstan & 4 & 2 & 4 & 4 & 1 & 15 \\
\hline Serbia & 3 & 3 & 3 & 2.5 & 3 & 14.5 \\
\hline Bulgaria & 3 & 1 & 3 & 3 & 3 & 13 \\
\hline Denmark & 3 & 0 & 3 & 3 & 3 & 12 \\
\hline Republic of Moldova & 3 & 1 & 3 & 2 & 3 & 12 \\
\hline Romania & 3 & 0 & 3 & 2 & 3 & 11 \\
\hline Albania & 2 & 2 & 1 & 2 & 2 & 9 \\
\hline Andorra & 3 & 0 & 0 & 3 & 3 & 9 \\
\hline Luxembourg & 3 & 0 & 3 & 0 & 3 & 9 \\
\hline
\end{tabular}

Table 2 continued on next page

country data, respectively. For Tajikistan, the Former Yugoslav Republic of Macedonia and Turkmenistan, no BMI data by age and sex were found but mean BMI data were available; so a distribution was constructed and a flat trend extrapolated from that single year of mean data (see Annex 2, available at http://content.karger.com/ProdukteDB/produkte. asp?doi=492115).

In most countries, only self-reported data were available. Measured data was found for only 20 of the countries. 
Pineda et al.: Forecasting Future Trends in Obesity across Europe: The Value of Improving Surveillance

Table 2. Continued

\begin{tabular}{|c|c|c|c|c|c|c|}
\hline Country & $\begin{array}{l}\text { No. of data } \\
\text { points }\end{array}$ & Measured & National & $\begin{array}{l}\text { Sample } \\
\text { size }\end{array}$ & $\begin{array}{l}\text { Freely available/ } \\
\text { accessible }\end{array}$ & Total \\
\hline Uzbekistan & 2 & 2 & 2 & 1 & 2 & 9 \\
\hline Hungary & 2 & 0 & 2 & 2 & 2 & 8 \\
\hline Bosnia and Herzegovina & 2 & 2 & 1 & 1 & 1 & 7 \\
\hline Georgia & 2 & 1 & 2 & 2 & $\mathbf{0}$ & 7 \\
\hline Montenegro & 1 & 1 & 2 & 1 & 2 & 7 \\
\hline Slovenia & 2 & 0 & 2 & 1 & 2 & 7 \\
\hline Belarus & 2 & 0 & 2 & 2 & 0 & 6 \\
\hline Cyprus & 2 & 0 & 2 & 2 & 0 & 6 \\
\hline Monaco & 0 & 0 & 0 & 0 & 0 & 0 \\
\hline San Marino & 0 & 0 & 0 & 0 & 0 & 0 \\
\hline Tajikistan & 0 & 0 & 0 & 0 & 0 & 0 \\
\hline The former Yugoslav Republic of Macedonia & 0 & 0 & 0 & 0 & 0 & 0 \\
\hline Turkmenistan & 0 & 0 & 0 & 0 & 0 & 0 \\
\hline
\end{tabular}

*Outliers were removed. Those countries with measured data are highlighted in bold.

Most of the data were obtained from nationally representative surveys, as indicated from the survey methods provided with the data. Some countries did not report sample sizes or reported the sample size only for the total study population or the total study population by sex rather than by age and sex.

Projected Prevalence of Obesity $\left(\geq 30 \mathrm{~kg} / \mathrm{m}^{2}\right)$ in 2025 for 53 Countries in the WHO European Region

The results show projected future increases in obesity for 45 of the 53 countries (fig. 1). The four countries that are estimated to have the highest obesity prevalence were: Georgia (77\%; 95\% CI 58-97\%); Romania (50\%; 95\% CI 43-57\%); and Serbia (47\%; 95\% CI 0-175\%) and Croatia (47\%; 95\% CI 26-68\%). Some countries had insufficient data, according to our data quality score, to interpret the trend with any degree of certainty.

From the 15 countries that had the best quality data (score $\geq 25$ points), obesity prevalence was projected to reach between 13 and $43 \%$ by 2025 . Ireland was predicted to have the highest prevalence, with $43 \%$ (95\% CI 28-58\%) of the population was predicted to be obese by 2025 , followed by Scotland, with $37 \%$ (95\% CI 29-45\%). However, the confidence intervals for Ireland were particularly wide. In England, Estonia, Greece, Scotland and Turkey, the prevalence of obesity was predicted to increase to $>30 \%$ by 2025 , while in France, Lithuania, the Russian Federation and Wales the prevalence was predicted to increase to 20-30\%. Italy had the lowest projected prevalence (13\% (95\% CI 10-16\%)) of the population (table 3).

\section{Discussion}

The prevalence of obesity across Europe is forecast to rise by 2025, which is likely to increase morbidity and mortality from noncommunicable diseases (NCDs) and place a significant strain on health systems and wider society [25]. In general, the prevalence of obesity tended to increase with age (detailed data available on request), which is worrying given that we know populations are generally aging across Europe [26]. Further, much of the data were self-reported so are likely to be underestimates of the true values [27]. 
Pineda et al.: Forecasting Future Trends in Obesity across Europe: The Value of Improving Surveillance

Fig. 1. Estimated prevalence of obesity ( $\geq 30 \mathrm{~kg} / \mathrm{m}^{2}$ ) to 2025 .

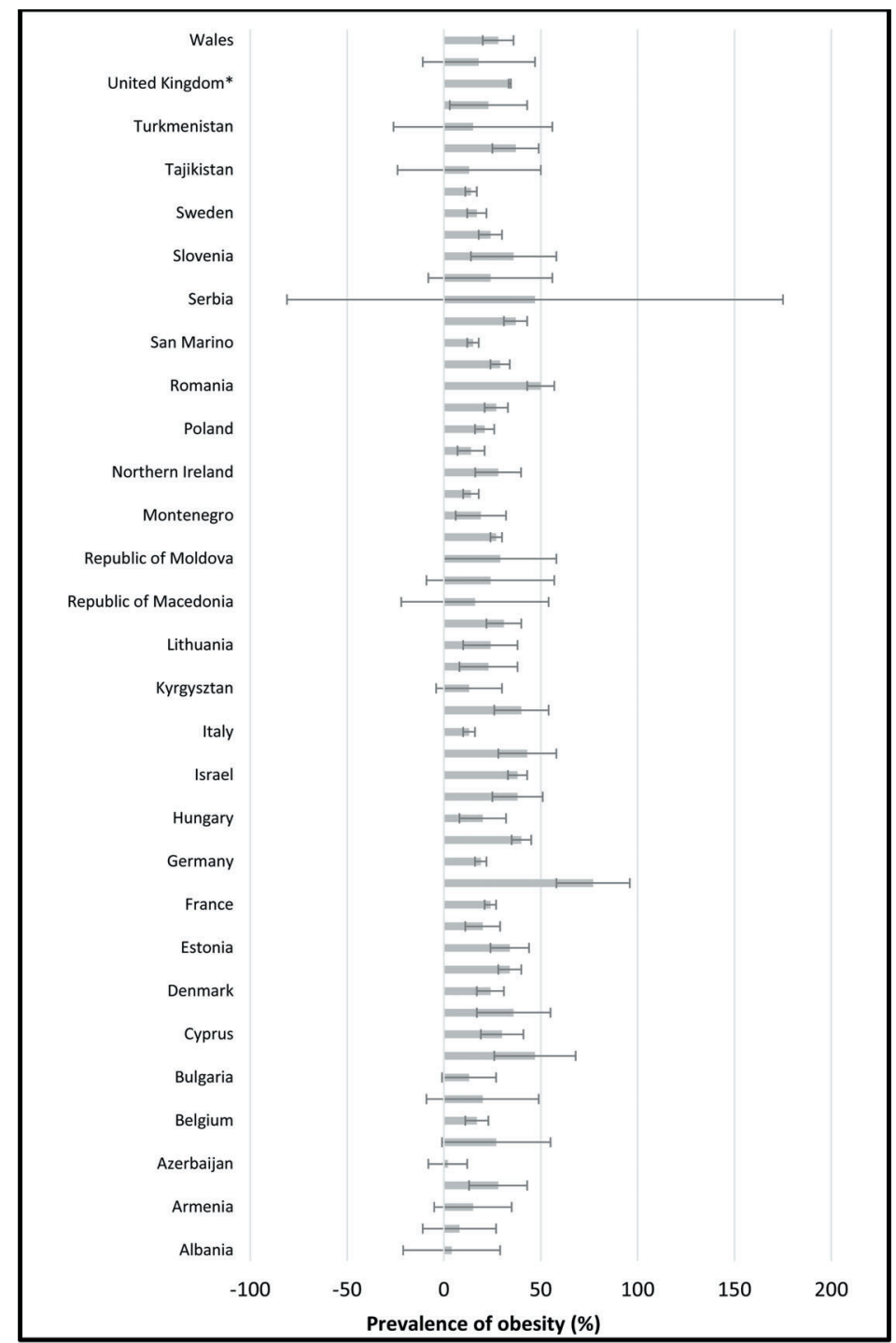

*United Kingdom estimates includes (England, Northern Ireland, Scotland and Wales)

No pattern of trends across Europe could be ascertained. The lowest prevalence of obesity was found in Azerbaijan (2\%) and Albania (4\%), while the prevalence in Bulgaria, Italy, Kyrgyzstan, The Netherlands, Norway, Switzerland and Tajikistan were all $<15 \%$ of the total population by 2025 , though with vastly varying data quality. In Croatia, Georgia, Greece, Ireland, Kazakhstan, Romania and Serbia, obesity prevalence was projected to be $\geq 40 \%$ of the total population by 2025 , though again with varying data quality meaning that the errors on some of these estimates were large. This study therefore builds on the work of the NCD-RisC estimates [4] and Global Burden of Disease study [28] by providing projections into the future and exploring the extent to which countries are likely to meet the WHO target. Annex 3 (available at http://content.karger.com/ProdukteDB/produkte.asp?doi $=492115$ ) provides a detailed comparison of our estimates with those of the WHO [29] showing they are broadly similar.

These projections indicate that the Member States in the WHO European Region are unlikely to meet the global obesity target to halt obesity at 2010 levels by 2025, adopted 
Table 3. Projected prevalence of obesity ( $\geq 30 \mathrm{~kg} / \mathrm{m}^{2}$ ) in 2025 for countries with high data scores in the WHO European Region
Pineda et al.: Forecasting Future Trends in Obesity across Europe: The Value of Improving Surveillance

\begin{tabular}{ll}
\hline Country & Prevalence of obesity \% by $2025(95 \% \mathrm{CI})$ \\
\hline England & $34(28 ; 40)$ \\
Estonia & $34(24 ; 44)$ \\
Finland & $20(11 ; 29)$ \\
France & $24(21 ; 27)$ \\
Germany & $19(16 ; 22)$ \\
Greece & $40(35 ; 45)$ \\
Ireland & $43(28 ; 58)$ \\
Italy & $13(10 ; 16)$ \\
Lithuania & $24(10 ; 38)$ \\
Netherlands & $14(10 ; 18)$ \\
Russian Federation & $29(24 ; 34)$ \\
Scotland & $37(31 ; 43)$ \\
Sweden & $17(12 ; 22)$ \\
Wales & $28(20 ; 36)$ \\
\end{tabular}

during the World Health Assembly in 2013. As a consequence, if the trajectory continues as projected, the rates of disease burden in Europe and the healthcare cost of its associated NCDs are also predicted to rise [4]. The results of this projection exercise demonstrates the importance of implementing policies on improving the food environment and the built environment to prevent and manage obesity and evaluating those that have been implemented.

Research indicates that upstream policies to change elements in the daily environment and combine actions for diverse sectors are likely to be more effective than policies that address personal responsibility exclusively [30-33]. The increased availability and affordability of sugar-sweetened beverages and foods high in saturated fats, sugars and/or salt and increased portion sizes have played important roles in increasing the prevalence of obesity $[11,34,35]$. Policies for reducing consumer demand and improving the nutritional quality of food will probably improve diets. Similarly, poor maternal nutrition leading to excess body weight before, during and after pregnancy plus insufficient breastfeeding and inappropriate complementary feeding also play a role in the development of obesity [36].

Effective food policies should seek not only to limit the availability and reduce the appeal of obesogenic foods but also increase the availability and affordability of healthy foods, such as fruit and vegetables as well as whole grains and foods with a lower content of saturated fats, transfats, sugars, and salt. Policies should create the right conditions for consumers to have healthier dietary preferences and make healthy choices $[37,38]$. It is recommended that policies focus both on influencing consumer demand (e.g. through clear, comprehensible labelling; using price as an incentive; reducing opportunities to promote foods high in fats, sugar and salt) and providing incentives to industry to improve the nutritional quality of the food supply (e.g. setting targets to remove excess nutrients, reducing calorie or portion sizes, and setting standards in settings such as schools and hospitals) [11,39]. Taxation of sugarsweetened beverages and high-calorie foods with low nutritional value may also be important in tackling obesity. Business incentives and subsidies for healthy fruit and vegetables could contribute to reducing the burden.

Policies should also address physical activity and the physical environment. The level of physical activity among children in Europe has decreased, with a steep drop among older children and adolescents (particularly girls) [40]. The priority should be to design policies to promote physical activity that include national and local urban planning and transport infrastructure to improve the accessibility, acceptability and safety of active transport, such as walking and cycling (e.g. cycle paths, pavements and pedestrian zones in urban areas). The 
creation and preservation of built and natural environments that support physical activity, including 'green' (grass and trees/vegetation) and 'blue' (water) areas, will encourage active recreation and increased physical activity [13].

The current and projected prevalence of obesity indicates that both prevention and management strategies are needed. Clinical practice guidelines for the prevention and treatment of obesity in adults and multidisciplinary approaches to obesity treatment in a chronic disease management framework have been published $[2,3,41]$. Obesity prevention and management strategies are required if substantial progress is to be made in reducing the prevalence of NCDs and achieving the targets [29, 42].

Our model relies on certain assumptions and decisions made by the research team, with expert input about the way individual BMI varies within a population [22]. The estimates of future prevalence are based on past trends with an assumption of no major changes in the future. Many European countries have put obesity prevention policies into action $[11,15,30$, 39, 43-46]. These include the European Food and Nutrition Action Plan 2015-2020, Investing in Children: the European Child and Adolescent Health Strategy 2015-2020 [47], and the childhood obesity strategy of the UK [48]. Progress in policy development has, however, been patchy, and more focus has been placed on 'downstream' interventions, such as education and public awareness than on introducing 'upstream' interventions to improve the social and physical environment.

To our knowledge, this paper provides the first scoring system measuring the quality and availability of nationally representative BMI data. The scoring system indicates the precision of our estimates, suggesting that future estimates would be even more accurate. A low score meant that the output could not be interpreted due to either lack of data or poor quality. The scoring system also includes a score for data availability/accessibility since in order for data to be considered it had to be readily available for analysis. Further work might validate this scoring system, add additional score, or provide some weighting for parameters deemed more important than others.

The scoring system illustrated that for many countries there were not enough data to interpret the estimates meaningfully, and variation in data meant comparisons between countries was not possible. Poor data not only reduces the accuracy of predictive models but also affects the ability of countries to evaluate their success in meeting the WHO goal of halting obesity at 2010 levels by 2025 . For example, much of the data were self-reported. We know that individuals often underreport their weight while over-reporting their height; therefore, the predictions of obesity are likely to be underestimated for the majority of countries [27, 49]. While adjusting self-reported values is possible, this study serves to highlight the variation in surveillance data across countries and the need for data harmonization across the WHO European region. It should also be noted that our scoring system did not include participation rates which could have provided a valuable indication as to how nationally representative the data collected were.

The scoring system can be used by countries to identify opportunities for improving data collection. The best-quality data were available in England, Finland, the Netherlands, the Russian Federation, and Scotland. However, of these, only England and Scotland had measured data and many of these surveys have shown falling participation rates over time. Therefore, all countries need to consider improving the quality of their surveillance data [50].

Nevertheless, our study indicates a worsening situation in relation to obesity prevalence across the WHO Euro region. This epidemic will have a consequential effect on the incidence of a range of obesity-related diseases such as coronary heart disease, stroke, cancer and musculoskeletal conditions, and subsequent impacts on the health system and wider society [51] summoning urgent action to curb the direction of these projections. Despite efforts to reverse the epidemic through strategies, initiatives, and programs [7,11-14] over the past 
Pineda et al.: Forecasting Future Trends in Obesity across Europe: The Value of Improving Surveillance

decade, additional and/or different approaches are required in order to observe more tangible effects.

While forecasting the prevalence of obesity is useful for planning policy and resource allocation, our study has both limitations and strengths. Differences in the survey methods used for anthropometric data collection may have affected the results as described above. However, our work highlights what is required by countries to enable more accurate estimates. The data for most countries were self-reported, although both self-reported and measured data were reported by Armenia, Austria, Azerbaijan, Bulgaria, Georgia, Germany, Ireland, Kazakhstan, Kyrgyzstan, Poland, Portugal, the Republic of Moldova, and Ukraine. Increasing the amount of measured data and standardizing collection practices will provide more accurate projections of the prevalence of obesity.

Including an alternative to BMI as a measure of obesity, such as waist circumference, was beyond the scope of this study but would be useful to include in future work to see how projections based on different measures compare. Given that waist circumference correlates highly with BMI when measured correctly [52], we would expect to obtain similar results. Further, to better understand differences by social group, future work could include projections of BMI trends by socioeconomic status.

This study focused on the adult population of the WHO European Region. Future work with a similar method will project trends in childhood obesity, based on the WHO European COSI, which has enabled harmonization of data in more than 30 countries in Europe [16]. Projections of trends in childhood obesity might also help us to understand the evolution of obesity trends resulting in adult obesity, as children and adolescents who are obese are much more likely than those who are not to be obese in adulthood [53-55]. Although interventions for children may be highly effective, they may not be sufficient to reduce or stall the rise in adult obesity, and a combination of policies targeting both children and adults are necessary.

This prediction exercise provides an important, necessary overview of the prevalence of obesity over time and the requirements for data collection in each country. The quality of BMI data across Europe is highly variable, with fewer than $50 \%$ of the 53 countries having measured nationally representative data and often not enough data to interpret projections meaningfully. Harmonizing data collection methods across Europe are necessary to improve surveillance and enable comparisons between countries. Greater, continued effort in implementing effective preventive and management policies is required from governments if we are to achieve the 2025 goal of halting obesity at 2010 levels by 2025 and reducing the subsequent burden of disease.

\section{Funding}

This research was funded by WHO Regional Office for Europe.

\section{Disclosure Statement}

João Breda, Jo Jewell and Gauden Galea are staff members of the WHO Regional Office for Europe. The authors alone are responsible for the views expressed in this publication, and they do not necessarily represent the decisions or the stated policy of the World Health Organization. 
Pineda et al.: Forecasting Future Trends in Obesity across Europe: The Value of Improving Surveillance

\section{References}

1 World Health Organization. World Health Statistics 2015. Luxembourg, WHO, 2015.

2 Public Health England. Data Factsheet: Adult Obesity International Comparisons. London, 2016. http://webarchive.nationalarchives.gov.uk/20170110165728/http://www.noo.org.uk/NOO_pub/Key_data (last accessed September 28, 2018).

3 World Health Organization: Health 2020:A European Policy Framework Supporting Action Across Government and Society for Health and Well-Being. Malta, WHO, 2012.

-4 NCD Risk Factor Collaboration: Trends in adult body-mass index in 200 countries from 1975 to 2014:a pooled analysis of 1698 population-based measurement studies with 19.2 million participants. Lancet 2016;387: 1377-1396.

-5 Flegal KM, Kit BK, Orpana H, Graubard BI: Association of all-cause mortality with overweight and obesity using standard body mass index categories: A systematic review and meta-analysis. JAMA 2013;309:71-82.

-6 Vos T, Barber RM, Bell B, Bertozzi-Villa A, Biryukov S, Bolliger I, et al: Global, regional, and national incidence, prevalence, and years lived with disability for 301 acute and chronic diseases and injuries in 188 countries, 1990-2013:a systematic analysis for the Global Burden of Disease Study 2013. Lancet 2015;386:743-800.

7 European Union: EU research Leads Battle against Obesity epidemic: European Commission, 2015 [cited 2015 22/09/2015]. Available from: http://ec.europa.eu/programmes/horizon2020/en/news/eu-research-leadsbattle-against-obesity-epidemic (last accessed September 28, 2018).

-8 Lette M, Bemelmans WJE, Breda J, Slobbe LCJ, Dias J, Boshuizen HC: Health care costs attributable to overweight calculated in a standardized way for three European countries. Eur J Health Econ 2016;17:61-69.

9 Wang YC, McPherson K, Marsh T, Gortmaker SL, Brown M: Health and economic burden of the projected obesity trends in the USA and the UK. Lancet 2011;378:815-825.

10 Frieden TR, Dietz W, Collins J: Reducing childhood obesity through policy change: acting now to prevent obesity. Health Affairs 2010;29:357-363.

11 World Health Organization: WHO European Food and Nutrition Action Plan 2015-2020. Regional Committee for Europe 64thSession.Copenhagen,2014www.euro.who.int/_data/assets/pdf_file/0008/253727/64wd14e_ FoodNutAP_140426.pdf (last accessed September 26, 2018)..

12 World Health Organization: Vienna Declaration on Nutrition and Noncommunicable Diseases in the Context of Health 2020. WHO European Ministerial Conference on Nutrition and Noncommunicable Diseases in the Context of Health 2020. Vienna, WHO, 2013.

13 World Health Organization: Physical Activity Strategy for the WHO European Region 2016-2025. Regional Committee for Europe 65th Session. Vilnius, 2015.

14 World Health Organization: Global Action Plan for the Prevention and Control of Noncommunicable Diseases 2013-2020. Geneva, WHO, 2013.

15 World Health Organization: The WHO Nutrition, Obesity and Physical Activity Database (NOPA). Geneva, WHO, 2011. www.euro.who.int/en/health-topics/disease-prevention/nutrition/news/news/2011/05/newdatabase-on-nutrition,-obesity-and-physical-activity (last accessed September 26, 2018).

16 Wijnhoven T, van Raaij V, Breda J. WHO European Childhood Obesity Surveillance Initiative. Copenhagen, WHO, 2014.

17 World Health Organization. The European Health Report 2015, Targets and Beyond - Reaching New Frontiers in Evidence. Geneva, WHO, 2015.

18 World Health Organization: WHO Global Database on Body Mass Index 2015. http://apps.who.int/bmi/index. jsp (last accessed September 28, 2018).

19 World Health Organization: BMI classification. Geneva, WHO, 2015 http://apps.who.int/bmi/index. jsp?introPage=intro_3.html (last accessed September 28, 2018).

20 World Health Organization Regional Office for Europe: Body mass index - BMI 2015. www.euro.who.int/en/ health-topics/disease-prevention/nutrition/a-healthy-lifestyle/body-mass-index-bmi (last accessed September 28, 2018).

21 Vos T, Barber RM, Bell B, Bertozzi-Villa A, Biryukov S, Bolliger I, et al: Global, regional, and national incidence, prevalence, and years lived with disability for 301 acute and chronic diseases and injuries in 188 countries, 1990-2013:a systematic analysis for the Global Burden of Disease Study 2013. Lancet 2015;386:743-800.

-22 Webber L, Divajeva D, Marsh T, McPherson K, Brown M, Galea G, et al: The future burden of obesity-related diseases in the 53 WHO European-Region countries and the impact of effective interventions: a modelling study. BMJ Open 2014;4:e004787.

23 World Health Organization: Global Database on Body Mass Index 2016. http://apps.who.int/bmi/ (last accessed September 28, 2018).

24 McPherson K, Marsh T, Brown M. Tackling Obesities: Future Choices - Modelling Future Trends in Obesity and the Impact on Health. Foresight Programme. London, Government Office for Science, UK Government, 2007.

25 World Health Organization: Obesity and Overweight 2015www.who.int/mediacentre/factsheets/fs311/en/ (last accessed September 28, 2018).

26 Zota A: Aging population in the European Union causes by the impact birth vs. death. Management Research Practice 2017;9:44-53.

27 Visscher T: Underreporting of body mass index in adults and its effect on obesity prevalence estimations in the period 1998-2001. Obesity (Silver Spring) 2006;14:2054-2063. 
Pineda et al.: Forecasting Future Trends in Obesity across Europe: The Value of Improving Surveillance

-28 Ng M, Fleming T, Robinson M, Thomson B, Graetz N, Margono C, et al: Global, regional, and national prevalence of overweight and obesity in children and adults during 1980-2013; a systematic analysis for the Global Burden of Disease Study 2013. Lancet 2014;384:766-781.

29 World Health Organization: Global Status Report on Noncommunicable Diseases 2014. Geneva, WHO, 2014.

-30 Roberto CA, Swinburn B, Hawkes C, Huang TT, Costa SA, Ashe M, et al: Patchy progress on obesity prevention: emerging examples, entrenched barriers, and new thinking. Lancet 2015;385:2400-2409.

31 Organisation for Economic Co-Operation and Development: Obesity and the Economics of Prevention: Fit not Fat. Paris, OECD Publishing, 2010.

32 Organisation for Economic Co-Operation and Development: Obesity Update. Paris, OECD Publishing, 2014.

-33 Huang TTK, Cawley JH, Ashe M, Costa SA, Frerichs LM, Zwicker L, et al: Mobilisation of public support for policy actions to prevent obesity. Lancet 385:2422-2431.

-34 Hollands GJ, Shemilt I, Marteau TM, Jebb SA, Lewis HB, Wei Y, et al: Portion, package or tableware size for changing selection and consumption of food, alcohol and tobacco. Cochrane Database Syst Rev 2015; 9:CD011045.

35 Marteau TM, Hollands GJ, Shemilt I, Jebb SA: Downsizing: policy options to reduce portion sizes to help tackle obesity. BMJ 2015;351:h5863.

36 Francesco B, Nikogosian H, Lobstein T: The Challenge of Obesity in the WHO European Region and the Strategies for Response: Summary. Geneva, WHO, 2007. www.euro.who.int/_data/assets/pdf_file/0008/98243/ E89858.pdf (last accessed September 28, 2018).

-37 Swinburn BA, Sacks G, Hall KD, McPherson K, Finegood DT, Moodie ML, et al: The global obesity pandemic: shaped by global drivers and local environments. Lancet 2011;378:804-814.

-38 Hawkes C, Smith TG, Jewell J, Wardle J, Hammond RA, Friel S, et al: Smart food policies for obesity prevention. Lancet 2015;385:2410-2421.

39 World Cancer Research Fund: NOURISHING framework London, 2016 www.wcrf.org/int/policy/nourishingframework (last accessed September 28, 2018).

40 Hallal PC, Andersen LB, Bull FC, Guthold R, Haskell W, Ekelund U, et al: Global physical activity levels: surveillance progress, pitfalls, and prospects. Lancet 2012;380:247-257.

41 National Institute for Health and Care Excellence: Obesity Overview. London,2016. https://pathways.nice.org. $u k / p a t h w a y s / o b e s i t y$ (last accessed September 28, 2018).

42 Public Health Evaluation and Impact Assessment Consortium: Evaluation of the implementation of the Strategy for Europe on Nutrition, Overweight and Obesity related health issues. Public Health Evaluation and Impact Assessment Consortium, 2013.

43 World Health Organization: Global Database on the Implementation of Nutrition Action (GINA). Geneva, WHO, 2012.

44 World Health Organization: Marketing of Foods High in Fat, Salt and suGar to Children: Update 2012-2013. Copenhagen, WHO, 2013.

45 World Health Organization Regional Office for Europe: Using price policies to promote healthier diets (2015). Copenhagen, WHO, 2015.

46 Hawkes C, Jewell J, Allen K: A food policy package for healthy diets and the prevention of obesity and dietrelated non-communicable diseases: the NOURISHING framework. Obes Rev 2013;14(suppl 2):159-68.

47 World Health Organization: Investing in Children: The European Child and Adolescent Health Strategy 20152020. Copenhagen, WHO, 2014

48 HM Government. Childhood Obesity: A Plan for Action. London, HM Government; 2016.

-49 Krul AJ, Daanen HA, Choi H: Self-reported and measured weight, height and body mass index (BMI) in Italy, the Netherlands and North America. Eur J Public Health 2011;21(4):414-419.

-50 Mindell JS, Giampaoli S, Goesswald A, Kamtsiuris P, Mann C, Männistö S, et al: Sample selection, recruitment and participation rates in health examination surveys in Europe - experience from seven national surveys. BMC Med Res Methodol 2015;15:78.

51 UK Health Forum \& Cancer Research UK: Tipping the Scales: Why Preventing Obesity Makes Economic Sense. 2016.www.cancerresearchuk.org/sites/default/files/tipping_the_scales_-_cruk_full_report11.pdf(lastaccessed September 28, 2018).

52 Gierach M, Gierach J, Ewertowska M, Arndt A, Junik R: Correlation between body mass index and waist circumference in patients with metabolic syndrome. ISRN Endocrinol 2014;2014:6.

-53 Simmonds M, Llewellyn A, Owen CG, Woolacott N: Predicting adult obesity from childhood obesity: a systematic review and meta-analysis. Obes Rev 2016;17:95-107.

-54 Sun SS, Liang R, Huang TT, Daniels SR, Arslanian S, Liu K, et al: Childhood obesity predicts adult metabolic syndrome: the Fels Longitudinal Study. Journal Pediatr 2008;152:191-200.

55 Lloyd LJ, Langley-Evans SC, McMullen S: Childhood obesity and risk of the adult metabolic syndrome: a systematic review. Int J Obes 2012;36:1-11. 